\title{
Extrañas interpretaciones de las sirenas en la iconografía renacentista y barroca. Un estudio desde la emblemática
}

Mํㅗㄹ López-Peláez Casellas

RESUMEN. En el presente estudio se analizarán representaciones de las sirenas que se alejan de las habituales en la iconografía renacentista y barroca. Frente a la imagen de la hermosa sirena con cola de pez, interpretada de forma tradicional como embaucadora y representante de los placeres, se comentarán imágenes en las que estas criaturas no sólo aparecerán representadas con un aspecto monstruoso sino incluso serán utilizadas para simbolizar valores a los que habían dejado de estar vinculadas varios siglos atrás: la fortaleza, la pureza y la capacidad oratoria.

Palabras clave: emblemas, sirena, iconografía, Renacimiento, Barroco.

ABSTRACT. In the following paper we will analyse several representations of mermaids that stay away from the common ones found in the Renaissance and Baroque iconography. From the image of the beautiful mermaid with a fish tail, interpreted from a traditional approach as deceitful and representing pleasures, we will comment on images where not only will they be depicted with a monstrous image but that will also be used as symbol of values that had stopped being related to them long ago: strength, purity and oratorical capacities.

Key Words: emblems, mermaids, iconography, Renaissance, Baroque.

A lo largo de los siglos las sirenas recibieron distintos significados. No sólo fueron consideradas monstruos vinculados al demonio y al pecado, sino también seres benefactores encargados de conducir las almas de los muertos. Durante el Renacimiento y Barroco se las vinculó frecuentemente a las armonías terrenales aunque habían sido ellas las encargadas de mover las esferas del universo y entonar el canto del cosmos en la República de Platón ${ }^{1}$. La

1 PlATÓN, Obras completas, Madrid, 1972, 617b. Con anterioridad a Platón los pitagóricos también se habían referido a las sirenas en este sentido; resaltaron de ellas su faceta musical y su conexión con los plane- sirena acabaría siendo utilizada como símbolo del pecado y de la vanidad del mundo, al igual que la música que ejecuta$\mathrm{ba}^{2}$.

tas y las hicieron las encargadas de conducir las almas errantes de los muertos para que pudieran encontrar su camino (F. BufFIÈRE, Les Mythes d'Homère et la Pensée Grecque, París, 1956, p. 478).

${ }^{2}$ Muy conocida y recordada en el Renacimiento y Barroco fue la interpretación que realizara san Isidoro en las Etimologías, en donde afirmaba que las sirenas en realidad habían sido prostitutas (ISIDORO DE SEVILLA, Etimologías, Madrid, 1983, xi 3, 30-31); este significado sería recogido siglos más tarde por Giovanni Boccaccio (G. BOCCACCIO, Genealogía de los dioses paganos, Madrid, 1983, VII XX). Menos frecuente resulta la 
En la iconografía renacentista y barroca se enfatizó de forma especial la vinculación de las sirenas con el placer y el engaño. Partiendo de la belleza atribuida a estos seres, potenciada en gran medida por su pertenencia al género femenino, y debido a la vinculación que mantenían con la música, se realizó una advertencia hacia lo que llegaba a través de los sentidos. El engaño que se derivaba tanto de su aspecto físico al ocultar la parte monstruosa de su cuerpo-, como de la aparente dulzura de sus melodías -que acababan conduciendo a la muerte a quienes las escucharan-, fue el aspecto especialmente resaltado de ellas. El enfrentamiento entre Ulises y las sirenas que recogiera Homero en la Odisea fue el ejemplo al que con más frecuencia se aludió desde la iconografía en general y desde la emblemática en particular cuando se representaban estas criaturas. La presencia del héroe posibilitaba exaltar dos de los principales valores sobre los que se asentaba la ideología contrarreformista, los de la virtud y la prudencia. Las sirenas, por su parte, se presentaban como fiel exponente del pensamiento que se tenía hacia las mujeres, o al menos hacia una gran parte de ellas, durante el Renacimiento y el Barroco. Se reunía en estos seres mitológicos las ideas de belleza y de mentira, de placer, de lujuria y de pecado.

En las siguientes páginas se analizarán ejemplos tomados de la emblemática en los que se realizó una interpretación diferente de estas criaturas y se resaltaron

alusión a las Sátiras de Horacio, en las que se vinculaba las sirenas a la pereza (Q. HORACIO, Satires, París, 1969, II, III). En un sentido similar, Guillaume le Clerc de Normandie, autor del popular Bestiaire divin, escrito en el siglo XIII, utilizaba las sirenas como símbolo de la gloria y del placer, incluyendo dentro de éste no sólo la lujuria, sino también el gusto por las riquezas y por la vida regalada (J. LECLERQ-MARX, La Sirène dans la pensée et dans l'art de l'Antiquité et du Moyen Âge. Du Mythe Païen au Symbole Chrétien, Bruxelles, 1997, pp. 108-109). características que habían quedado relegadas o incluso olvidadas con el paso de los siglos ${ }^{3}$. Se destacará, en concreto, la conexión entre las sirenas y la capacidad oratoria, las ideas de renovación, pureza y fortaleza. Todos estos significados serán los resaltados en sus tratados por intelectuales pertenecientes a entornos diferentes: el alemán Joachim Camerarius, el holandés Pieter Cornelisz Hooft, los tratadistas italianos Paolo Giovio y Giulio Cesare Capaccio y el inglés Henry Peacham.

En el Dialogo dell'Imprese Militari et Amorose, publicado por primera vez en Roma en 1555, el humanista italiano Paolo Giovio utilizaba a la sirena con uno de estos significados inusuales ${ }^{4}$. Se trata de la empresa que tiene como mote "Contemnit Tuta Procellas" ${ }^{5}$ y estaba dedicada a Stefano Colonna, a quien Giovio se refiere en el comentario que acompaña al grabado como al "valoroso e magnanimo Capitan Generale del Duca Cosimo". La imagen de la empresa fue elaborada por Giovio partiendo de motivos heráldicos que estaban vinculados a dos ramas muy conocidas de esta ilustre familia italiana: la columna coronada y la sirena de dos colas ${ }^{6}$. Debemos señalar

\footnotetext{
${ }^{3}$ Las obras pertenecientes al género de la emblemática se caracterizan por gozar de una doble condición, ya que pueden ser consideradas como elemento iconográfico y como literario. Cada uno de los emblemas que las componen están formados por un grabado o pictura, un epigrama y una sentencia un tanto críptica denominada lema o mote.

${ }^{4}$ P. GIOvio, Dialogo dell'Imprese Militari et Amorose, Vinegia, 1557, p. 131.

${ }^{5}$ 'Libre de temor, la sirena desprecia las tormentas' (Traducción de la autora).

${ }^{6}$ Una sirena de dos colas protagoniza el escudo de los Colonna que está colocado en la Porta Romana de Paliano (la imagen se puede ver en http://www.romeartlover.it/Paliano.html; consultado el 5/IX/2006). Tanto la sirena de dos colas como la columna coronada forman parte de la decoración del palacio que el Papa Martinus V (Oddone Colonna) construyó en su ciudad natal, Genazzano (http://www.romeartlover.it/Genazza.html; consultado el 5/IX/2006).
} 
que esta extraña fisonomía de la sirena no fue inusual durante la Edad Media. Desde el siglo XI, y especialmente durante el XII, coexistieron representaciones de estas criaturas con un número desigual de colas que oscilaba entre una y tres. De entre ellas fue la sirena provista de dos colas la que más se reprodujo, en especial en la escultura, debido a la simetría que creaba con su cuerpo ${ }^{7}$.

Mediante la alusión a la fortaleza de la sirena que se realiza en el texto colocado a continuación del grabado, Giovio halagaba al noble italiano al que estaba dirigida la empresa. Como señala, la sirena "ch'egli sprezzaua l'auuertsità, comme confidatosi nel valor suo", es decir, "rompia la adversidad confiando en su valor", según la traducción al español que pocos años más tarde realizara Alonso de Ulloa y que diera lugar al Dialogo de las Empresas Militares y Amorosas ${ }^{8}$.

La pictura está protagonizada por una única sirena que aparece situada entre las famosas columnas de Hércules. En medio de un mar algo encrespado, la criatura permanece impasible manifestando el amor que, desde la Edad Media, se decía que sentían estas criaturas por las tempestades. Esta cualidad ya fue resaltada en bestiarios como el de Philippe de Thaün, en donde se aseguraba que las sirenas lloraban con el buen tiempo y cantaban en la tempestad, “Qu'ele chante en tempeste/ (...) La sereine en bel tens/ Plure..." ${ }^{9}$. La presencia de la sirena, exenta de cualquier connotación sexual y de alusiones musicales, estaría encaminada, por un lado, a enfatizar la

-

7 J. LECLERCQ-MARX, La Sirène dans la pensée..., pp. 102-103.

${ }^{8}$ P. GIOvio, Dialogo de las empresas militares, y amorosas compuesto en lengua italiana por Paulo Giovio todo nuevamente traducido en romance castellano por Alonso de Ulloa, León de Francia, 1561, pp. 137-138.

${ }^{9}$ J. LeCLERCQ-MARX, La Sirène dans la pensée..., p. 111. tempestad y la peligrosidad del mar y, por otro, a señalar la firmeza y la estabilidad que era capaz de mantener en esos momentos adversos. Las columnas de Hércules, que marcaban los confines del mundo, parecen ser una referencia tanto a la seguridad de las sirenas como a los peligros de lo desconocido.

El tratadista alemán Joachim Camerarius utilizó la sirena de Giovio y la desvinculó de la familia Colonna en su tratado Symbolorum \& Emblematum. La obra estaba dividida en cuatro centurias que fueron apareciendo de forma sucesiva (desde 1593 hasta 1605$)^{10}$, no siendo hasta la publicación de la edición póstuma de 1605 cuando se reunieron los cuatro tratados en un extenso volumen. De ello se encargaría el hijo del autor, Ludwig Camerarius, quien también finalizaría la cuarta centuria que había quedado inacabada ${ }^{11}$. Manteniendo el mote de Giovio, "Contemnit Tuta Procellas", Camerarius incluyó este emblema en el cuarto de los tratados, el dedicado a los reptiles y a los animales acuáticos ${ }^{12}$.

En el comentario del emblema, Camerarius no sólo admite la poderosa influencia que había recibido por parte de la empresa de Giovio sino que también adop-

\footnotetext{
${ }^{10}$ Publicadas todas ellas en la ciudad de Nuremberg, los títulos y fechas de las distintas centurias son: Symbolorum \& Emblematum ex Re Herbaria (1593); Symbolorum \& Emblematum ex Animalibus Quadrupedibus (1595); Symbolorum \& Emblematum ex Volatilibus et Insectis (1596-1597); y, por último, Symbolorum \& Emblematum ex Aquatilibus et Reptilibus (1604-1605).

${ }^{11}$ J. Chatelain, Livres d'Emblèmes et devises. Une Anthologie (1531-1735), París, 1993, p. 89.

12 J. CAMERARIUS, Symbolorum \& Emblematum Centuriae tres. I. Ex herbis \& stirpibus. II. Ex animalibus quadrupedibus. III. Ex volatilibus \& insectis. Editio secunda, auctior \& accuratior. Accesit noviter Centuria IV. Ex aquatilibus $\mathcal{E}$ reptilibus, 1605, LXIV 65. Aunque en esta edición no se hace referencia al lugar de impresión del tratado, el investigador John Landwehr se decanta por la ciudad de Nuremberg (J. LANDWEHR, German Emblem Books. 1531-1888, Utrecht, 1972, p. 166).
} 
ta el significado que el tratadista italiano le había otorgado. Así, señala que la figura de la sirena y el entorno en el que es representada hace referencia a cómo se debe hacer frente a las adversidades. Apoya su argumentación reproduciendo textos procedentes de distintas autoridades; recuerda un fragmento del Edipo de Séneca, en el que se aconseja sobre la forma de enfrentarse a los contratiempos y se afirma que es propio de reyes elegir siempre el camino más difícil; reproduce unos versos tomados del Elogio de Justino de Coripo, en donde se destaca los beneficios de mantener el paso firme y no alejarse del buen camino o del camino señalado; y finaliza con un texto de Quinto Curcio en el que se destacan las virtudes Alejandro Magno. El mensaje que se transmite va encaminado a resaltar la importancia de no retroceder ante la dificultad, por grande que ésta sea.

La pictura del emblema de Camerarius resulta ser idéntica, salvo pequeños detalles, a la de Giovio; se trata de una ilustración de forma circular dotada de un adorno en los bordes a modo del de las gráfilas de las monedas. Las diferencias que se advierten entre los grabados de Giovio y de Camerarius no son numerosas y tienen que ver con la presencia de los vientos, las coronas sobre las torres (que son eliminadas en la imagen de Camerarius, quizá para evitar esa conexión tan directa con el motivo heráldico de los Colonna), o la superficie sobre la que éstas se asientan. El epigrama, escrito en latín y colocado bajo el grabado, consiste en apenas dos versos: "Fluctibus en mediis lascivit florida Siren,/ Hanc mare sed fortem sors inimica beat" ${ }^{\prime 13}$.

Giulio Cesare Capaccio (1552-1634) ofrece en su Trattato dell'Imprese otra interesante imagen de una sirena. La obra fue

\footnotetext{
13 'Ahí en medio de las olas tienes a la Sirena brillante y espléndida; y la suerte contraria en el mar la hace fuerte y feliz' (Traducción de la autora).
}

publicada por primera vez en Nápoles en 1592 y está dedicada a un magistrado de esta ciudad, Giovanni Battista Crispo. La sirena a la que nos referimos está incluida en el primero de los libros que forman el tratado y está acompañada de un mote y un breve comentario ${ }^{14}$. Tras el grabado, Capaccio añade una breve descripción de lo que se puede ver en la imagen: "vna Sirena in mezzo a Veseuo acceso fà stillar late dalle mamme", es decir, una sirena en medio del Vesubio extrayéndose leche de una de sus mamas. Tras estas palabras, el tratadista italiano coloca el mote de la empresa, “Dum Vesuvii siren incendia mulcet"15.

El grabado, de forma ovalada, está protagonizado por una sirena alada con patas de ave y torso de doncella. Colocada en el centro de la composición, se toca los pechos con las manos para extraer de ellos la leche con la que apaga el fuego que la rodea y baña el instrumento musical que se encuentra a sus pies, una lira da braccio ${ }^{16}$. Este instrumento, más que cualquier otro del Renacimiento, fue asociado a la música de la Antigüedad, lo que contribuyó a que se le diera un significado alegórico tanto en las artes visuales como en la literatura emblemática del Renacimiento y Barroco ${ }^{17}$.

\footnotetext{
${ }^{14}$ G. C. CAPACCIO, Del trattato dell'imprese di Giulio Cesare Capaccio. Libro Terzo, Nápoles, 1592, I fo 24.

15 'Mientras la sirena apaga el fuego del Vesubio' (Traducción de la autora).

${ }^{16}$ Al igual que la inmensa mayoría de los intelectuales de su tiempo, Capaccio creyó que la lira da braccio era un instrumento antiguo debido a que alguna de sus características hacían recordar la lira de la que se hablaba en los tratados de la Antigüedad: el que fueran siete el número de cuerdas del instrumento o el que algunas de ellas sonasen en toda su longitud. Además se creía que el plectro de la antigua lira y el de la kithara era parecido al arco, lo que no sería refutado hasta finales del siglo XVI por Vicenzo Galilei (V. GALILEI, Dialogo della musica antica e della moderna, Fiorenza, 1581, p. 130).

${ }^{17}$ Jean Baudoin representó al músico Orfeo tocando una lira da braccio para simbolizar la Filosofía en su Recueil d'emblêmes (J. BAUDOIN, Recueil d'emblêmes, ou
} 
En el análisis que Emanuel Winternitz realiza de esta empresa denomina este tipo de representación "lacteal baptism" y lo pone en conexión con una imagen que aparece reproducida en la parte posterior de un espejo: la conocida como Patera Martelli, obra cuyo origen siendo un misterio. Este bautismo lácteo está presente igualmente en el Purgatorio de Dante, donde es el propio Homero el bautizado, o en un cuadro flamenco anónimo del siglo XVI, Musical Allegory, en el que es un joven músico, instrumentista de una viola de cinco cuerdas, el que recibe la leche ${ }^{18}$. En su estudio, Winternitz dirige la atención hacia una de las representaciones que Cesare Ripa realizó de la Poesía en su Iconologie. Este iconólogo italiano no sólo describe la imagen como la de una joven que muestra unos pechos desnudos y repletos de leche, sino que además añade que "(l)os pechos llenos de leche muestran la fecundidad de los conceptos e invenciones que conforman el alma de la Poesía" ${ }^{19}$. Teniendo en cuenta todos estos elementos, la escena se podría interpretar no sólo como un bautismo alegórico del instrumento del músico por parte de la sirena, como indica Winternitz ${ }^{20}$, sino que también se podría poner en conexión con las ideas de pureza y renovación a las que esta criatura estaba vinculada en la Antigüedad. Todavía en la Edad Media persistían vestigios de la antigua consideración de la sirena como psicopompo, siendo un claro ejemplo de ello uno de los

Tableaux des Sciences \& des Vertus morales París, 1685, pp. 92-100). Con anterioridad, el teórico de la música Franchinus Gaffurius había puesto la lira da braccio en manos del dios Apolo para hacer referencia a la música cósmica (F. GAFFURIUS, De harmonia musicorum instrumentorum opus, Mediolani, 1518, fo 94).

${ }^{18}$ Estos datos proceden de E. WINTERNITZ, Musical Instruments and Their Symbolism in Western Art, New York, 1979, pp. 202-210.

${ }^{19}$ C. RIPA, Iconología, Madrid, 1996 (repr. ed. Siena, 1613), II, p. 219.

${ }^{20}$ E. WinTERNITZ, Musical Instruments..., p. 205. sermones de Honorio de Autum en el que esta criatura aparecía estrechamente vinculada a otros seres dotados de un claro valor simbólico, el pelícano y el ave féni $x^{21}$.

Una imagen similar a la descrita en el emblema de Capaccio se encuentra en uno de los sellos que forman parte del tratado Opus medico-chymicum de Johann Daniel Mylius. Publicado en Frankfurt en 1618 por Lucas Jennis, el tratado está formado, como indica su título, por tres partes: Basilica medica, secundus Basilica chimica, tertius Basilica philosophica. Cada uno de estos libros se caracteriza por su diferente temática, a saber: médica, química y filosófica. El emblema en el que se utiliza la figura de la sirena es uno de los ciento sesenta que están incluidos en la tercera parte del tratado y uno de los denominados "Sellos de los Filósofos". Como señala Santiago Sebastián, la iconografía de estos sellos se caracteriza por la fuerte presencia de símbolos procedentes de la alquimia y por su contenido hermético $^{22}$. El grabado, de forma circular, está dominado por la figura de una sirena coronada provista de dos colas que, al igual que la anterior de Capaccio, extrae leche de sus pechos exprimiéndolos con ambas manos. En la parte inferior del grabado se expone el mote del emblema, "Aurora Consurgens philosophica", mientras que un verso latino rodea la ilustración: “Omnibus rebus inest suus innatus Spiritus, quo vegetatur et crescit $^{\prime 23}$. El significado de la imagen, como parece fuera de toda duda, estaría conectado nuevamente con esa idea de

\footnotetext{
${ }^{21}$ Referencias a este sermón se pueden encontrar en K. MEYER-BAER, Music of the Spheres and the Dance of Death. Studies in Musical Iconology, New Jersey, 1974, p. 283.

${ }^{22}$ S. SEBAStIÁN, Alquimia y Emblemática. La fuga de Atalanta de Michael Maier, Madrid, 1989, p. 136, 151.

23 "Al despuntar el Alba" y "En todas las cosas reside un Espíritu propio que les confiere vida y las hace crecer". Estas dos traducciones son las ofrecidas por S. SEBASTIÁN, Alquimia y Emblemática ..., p. 157.
} 
regeneración a la que hicimos referencia en el párrafo anterior.

El tercer emblema de la sirena que vamos a analizar está incluido en una obra de temática amorosa, Emblemata Amatoria, Afbeeldingen van Minne, Emblesmes d'Amour (Ámsterdam, 1611) ${ }^{24}$. El tratado fue compuesto por Pieter Cornelisz Hooft (15811647) y está integrado por treinta excelentes grabados realizados en cobre y dotados de textos en latín, holandés y francés. Aunque se desconoce la autoría de las ilustraciones, éstas pudieron haber sido obra de Crispijn le Blon o P. Serwouter ${ }^{25}$.

El emblema está formado por un mote escrito en tres lenguas: en latín, "Verba dedit"; en holandés (la lengua natal del autor), "Niet aen ghevangen"; y en francés, "En Amour n'y point d'asseurance" ${ }^{26}$. La parte literaria se ve completada por tres dísticos escritos en estos mismos idiomas y encabezados por sus respectivos motes.

El grabado está protagonizado por la figura de Amor. De pie y en la orilla del mar, sostiene y muestra una red en la que lleva los cuatro vientos que ha atrapado. Mientras, en el mar, en un segundo plano, está siendo cazada una sirena. Aunque éstas son las dos escenas principales que se representan en la imagen, creemos que el mensaje del emblema no procede tan sólo de estos elementos sino que junto a ellos coexisten otros que refuerzan el significado del conjunto. Nos referimos a las conchas

-

24 P. C. HOOFT, Emblemata Amatoria, Afbeeldingen van Minne, Emblesmes d'Amour, Ámsterdam, 1611, pp. 60-61.

${ }^{25}$ B. BECKER-CANTARINO, "The Emblemata amatoria: Implications for the Index Emblematicus", The European Emblem. Towards an Index Emblematicus, Waterloo, 1980, p. 73.

${ }^{26}$ Las traducciones de los motes, en el orden en el que han sido reproducidos, son las siguientes: 'Sólo promesas', 'No ha cogido ninguno' y 'No hay seguridad en el amor' (Traducción de la autora). vacías que están dispuestas en la orilla y a los pies de Amor, o al contraste entre las nubes y el sol que envuelve toda la escena del grabado.

Los textos que acompañan la pictura se refieren de forma más o menos directa a la escena principal. Un buen resumen de la idea del autor hacia el sentimiento amoroso es ofrecido en el primero de los dos versos que componen el texto escrito en francés, en el que de forma tajante el autor afirma que "S'asseurer en Amour c'est estre temeraire"; es decir, es temerario pretender tener seguridad en el amor. El texto latino, por su parte, se centra más en lo agradable que resultan las palabras y las promesas de los enamorados, que son identificados con los vientos que Cupido ha introducido en su red: "Verba bona auribus incantata haud verba merentis/ Bella irretiti praemia sunt Zephyri"27.

Mario Praz señala como antecedente iconográfico de la imagen situada en primer plano, la de Amor cazando con su red, uno de los emblemas incluidos en Le Théâtre des bons engins de Guillaume de la Perrière, en concreto el número $36^{28}$. El significado de la imagen representada en el emblema resulta bastante obvio; mediante ella de la Perrière hace referencia no sólo a los trabajos inútiles sino también a los imposibles de realizar. Creemos, sin embargo, que el significado de la imagen del emblema de Hooft pudiera ir aún más lejos y no limitarse tan sólo a señalar esa imposibilidad de tener seguridad en el amor; podría verse ampliado por el detalle ya mencionado de las conchas vacías que se encuentran en la orilla y a los pies del joven dios. Como ya señalara Santiago Sebastián, las conchas, las

\footnotetext{
27 'Palabras buenas que encanten los oídos, no palabras que despierten guerras, son debidas a Céfiro cuando es atrapado en la red' (Traducción de la autora).

${ }^{28}$ M. PRAZ, Imágenes del..., pp. 142-143.
} 
caracolas y las estrellas de mar fueron elementos muy utilizados en los cuadros de naturaleza muerta para aludir a la vanitas. Debido a la importancia que, como señala este investigador, tuvieron estos cuadros en el arte holandés del siglo XVII, creemos que pudiera ser acertado considerar que Hooft al utilizar las conchas vacías buscaba esa misma interpretación ${ }^{29}$. Este tratadista contaba además con el importante antecedente que suponía uno de los emblemas incluidos en el Symbolorum et emblematum de Joachim Camerarius, cuyo grabado estaba protagonizado por una playa sembrada de conchas vacías que simbolizan, como se señala en su epigrama, la transitoriedad de la vida humana ${ }^{30}$.

Uno de los principales problemas que conlleva el análisis del grabado de un emblema es el de la discriminación de los elementos que poseen valor simbólico de los que no lo tienen. En ocasiones es difícil determinar qué elementos están dotados de un significado más allá del que su forma transmite o, lo que es lo mismo, si un elemento es susceptible o no de ser interpretado. Este es el problema que nos encontramos ante uno de los detalles que están presentes en el grabado de este emblema: el de

${ }^{29}$ S. SEBASTIÁN, Emblemática e historia del arte, Madrid, 1995, pp. 331-332. La interpretación que hemos realizado de las conchas del grabado como símbolo de la vanitas difiere de la señalada por Santiago Sebastián. En opinión de este tratadista, la lectura de las conchas en este emblema debe vincularse al Ars Amandis de Ovidio y a los sinsabores que ocasiona el amor; la sirena, según este autor, aludiría al falso amor, tal como interpretara Cesare Ripa en unas de sus alegorías. El significado que hemos extraído del conjunto del emblema también difiere del señalado por este investigador; en su opinión, mediante este emblema, Hooft alude a los sinsabores que ocasiona el amor debido a lo vanas que resultan las promesas de los enamorados (S. SEBASTIÁN, La mejor emblemática amorosa del Barroco. Heinsius, Vaenius y Hooft, Ferrol, 2001, p. 184).

${ }^{30}$ J. CAMERARIUS, Symbolorum \& Emblematum... , 1605, IV 56. la pareja formada por el sol y las nubes y las luces y sombras que crean. Mediante ellos el autor podría aludir nuevamente a la idea de cambio y de transitoriedad de la vida, reforzando, por tanto, el significado principal, el de que no hay seguridad en el amor y no puede haberla porque en la vida todo está sujeto a modificación. Es por ello por lo que, como indica Hooft en el epigrama, las promesas de los amantes son necesariamente vanas.

La presencia de la sirena en el grabado no está conectada a la música ni relacionada con ninguna de las habituales interpretaciones con las que se dota a estos seres. Simplemente la sirena sirve para reforzar el significado transmitido por la imagen principal: intentar apresar a una sirena en su medio resulta tan imposible como intentar retener el amor.

En último lugar nos vamos a referir a la más extraña imagen de la sirena que se abordará en este artículo, la incluida en Emblemata Varia, la obra dedicada al género de la emblemática menos conocida de Henry Peacham o, como él mismo se hace llamar en el frontispicio del tratado, Henrico Peachamo (1578-ca. 1644). Se trata de un manuscrito que, sin fechar, se encuentra en la actualidad en el Folger Shakespeare Library, en Washington (donde está catalogado como MS. V. b. 45), y cuya única edición conocida ha sido la facsimilar realizada por John Horden ${ }^{31}$. Compuesto, según Alan Young, alrededor de 1621, el tratado es más breve que los otros que Peacham dedicara a la emblemática, los más conocidos Basilikon Doron y Minerva Britanna. La gran diferencia con ellos estribaría en que los veinte emblemas que integran la Emblemata Varia son de nueva creación. Al igual que con sus otros tratados, con éste Peacham pretendía obtener beneficios de su

\footnotetext{
${ }^{31}$ H. PEACHAM, Emblemata Varia, London, 1976.
} 
destinatario, sir Julius Caesar. Aunque no se conocen las prebendas que pudo obtener con esta acción, en otra de sus obras, The Compleat Gentleman, el autor reconoce quedar obligado a este dignatario. Nada pudo hacer, sin embargo, para evitar morir en la pobreza $^{32}$.

En líneas generales se puede señalar que los emblemas que integran el tratado, veinte en total, están compuestos por un mote, una ilustración y un breve epigrama latino formado por cuatro versos. Aunque algunos de ellos tienen anotaciones en los márgenes y epigramas de una mayor extensión, el que se va a analizar, el que tiene como mote "Sepulchrum Isocratis" ${ }^{33}$ se ajusta a esta norma general. Su colocación al final del tratado parece en un principio ser la usual, ya que los emblemas escogidos para cerrar las obras solían, en general, estar referidos a la muerte como medio de recordar lo pasajera que resulta la vida. No creemos, sin embargo, que ese sea el principal significado que se pueda encontrar en este emblema.

Por lo que respecta a la pictura, lo primero que hay que señalar es el hecho de que, tanto ésta como el resto de las que se incluyen en el tratado, estén dibujada a tinta. Las ilustraciones, de muy poca calidad, debieron ser realizadas por el propio autor, quien fue un gran amante del dibujo. La sirena que se representa en la imagen no sólo se encuentra fuera de su medio, sino en una posición que resulta del todo inusual. Está colocada sobre una figura triangular que a su vez está dispuesta sobre lo que debemos considerar, si nos atenemos al mote, un sarcófago. Debido a su mal estado de conservación, pocos son los detalles que se pueden señalar de la sirena aparte de su

\footnotetext{
${ }^{32}$ Estos datos proceden de la introducción, sin paginar, realizada por Alan R. Young, a la mencionada edición facsimilar de Emblemata Varia (1976).

33 'Tumba de Isócrates' (Traducción de la autora).
}

cola de pez, aunque debido a su tamaño no parece que éstos deban ser demasiado importantes; parece que es la propia figura de la sirena, y no los atributos con los que pudiera estar dotada, la que aporta el significado al emblema.

Debajo del grabado está colocado el epigrama. Formado por cuatro versos latinos, informa de que el túmulo contiene al célebre Isócrates, cuya boca destilaba el néctar cecropio (es decir, de Atenas), y añade a continuación: "Crecopium Cuius stillabat Nectar ab ore/ Nobilis hoc tumulo conditur ISOCRATES/ Infignit cineres SYREN quia melleus ore/ Vicisse his cantu fertur et eloquio" ${ }^{\prime 34}$.

La presencia de una sirena sobre un sarcófago no es novedosa; parece que se dispuso una sobre la tumba de Sófocles para hacer referencia al encantamiento que producía su poesía ${ }^{35}$ y también se colocó otra sobre la del mencionado Isócrates o, al menos, así lo recoge Flavio Filóstrato de Lemnos. Fue una obra de este autor, Vida de los Sofistas, la que, en nuestra opinión, Peacham debió utilizar para elaborar su emblema. En este tratado se afirma que sobre la tumba de Isócrates, filósofo discípulo de Gorgias, se colocó una sirena en actitud de cantar para simbolizar "el poder de persuasión de este hombre, facultad que unía al empleo de normas y usos retóricos" ${ }^{\prime 36}$.

La conexión que se produce en este emblema entre la sirena, la muerte y la elo-

\footnotetext{
34 'Engalana sus cenizas la sirena, porque se cuenta que él, dulce de palabra, la derrotó con su canto y su elocuencia' (Traducción de la autora).

35 www.galeon.con/filoesp/Akademos/colabora/ math_iso.htm; consultado el 7/IX/2006.

${ }^{3 \overline{6}}$ F. FILÓSTRATO, Vidas de los sofistas, Madrid, 1982, I 17, vv. 503-504. No es ésta la única conexión que en la Antigüedad se produjo entre un filósofo y la elocuencia; Aristón de Quíos, discípulo de Zenón, era apodado "La Sirena" por su capacidad oratoria (L. DE ULIERTE, "Sirenas: del mito a la publicidad", La mujer en el arte español, Madrid, 1997, p. 560).
} 
cuencia-oratoria resulta especialmente interesante ya que significa apelar no sólo a la antigua concepción de estos seres como psicopompos, sino también a la vinculación entre música y lenguaje existente en la Antigüedad griega. Con respecto a la primera conexión apuntada, la referida a la muerte, hay que señalar que la colocación de sirenas en estelas funerarias hacía referencia al hecho de que estas criaturas se encargaran de guiar las almas de los difuntos para que éstas no se perdieran en su ascenso a los cielos. Como indica la investigadora Kathi Meyer-Baer, era especialmente típico en las estelas que se realizaron durante el siglo IV a. C. que se colocaran una o dos sirenas con aspecto de ave tocando la cítara en la parte superior de un triángulo ${ }^{37}$, descripción ésta que, como se puede apreciar, guarda una extraordinaria similitud con el grabado de Peacham. Según lo apuntado, parece que esta antigua tradición que vinculaba a las sirenas a los muertos en su calidad de psicopompos y las disponía sobre los sarcófagos (tal como se aprecia en el grabado) o las relacionaba con la elocuencia, influyó tanto en la colocación de la sirena a la que se refiere Filóstrato en su tratado como en el emblema de Henry Peacham.

Como señalamos en el párrafo anterior, la vinculación que se realiza en el epigrama entre el canto de la sirena y la elocuencia está basada en gran medida en la estrecha vinculación que existía en la antigua Grecia entre la música y la poesía. Debe ser tenido en cuenta que hasta el siglo $\mathrm{V}$ a. C., en el que la música empezó a desvincularse del arte poético, ambas se basaban en las características del lenguaje ${ }^{38}$.

\footnotetext{
${ }^{37}$ K. MEYER-BAER, Music of the Spheres... , pp. 183, 245-246.

${ }^{38}$ A. MARTíN, "Música, Pasión, Razón: La Teoría de los Afectos en el Teatro y la Música del Siglo de Oro", Edad de Oro, XXII, 2003, pp. 321-328.
}

Pudiera ser que Peacham, al afirmar en el emblema que el sabio griego había vencido a las sirenas, pretendiera equipararlo a otro personaje que era conocido, al igual que él, por su elocuencia y que también había resultado vencedor en su enfrentamiento con estas criaturas, el músico Orfeo $^{39}$. Sin embargo, el hecho de que en el epigrama no se las califique como seres monstruosos ni se considere que su canto sea engañoso, hace pensar que las sirenas de este emblema no son el mismo tipo de criaturas a las que se enfrentara el músico tracio. La consideración en la que se tiene a la sirena en esta ocasión se mantiene alejada de la interpretación moral que se popularizó de estos seres o de la imagen que de ellas nos presentan fuentes como Homero. Su presencia en el texto de Filóstrato y en el emblema de Peacham, podría estar motivada por su consideración como seres elocuentes y sabios; la victoria de Isócrates sobre ellas debe interpretarse como un ensalzamiento del valor del orador griego.

La aludida conexión entre las sirenas y la sabiduría fue más popular de lo que se pudiera pensar en un principio. Ovidio en sus Metamorfosis ya se había referido a las "doctas Sirenas" ${ }^{40}$ y, de igual forma, Cicerón las erigía en símbolo del saber y aprender. En su tratado De finibus, este poeta romano señalaba que las sirenas tentaron a Ulises ofreciéndole la sabiduría ${ }^{41}$. Según esta antigua interpretación, que se aparta del significado moral más extendido, las sirenas con su canto hacían olvidar las cosas terrestres para inspirar en su lugar el amor por lo espiritual. En su interesante

\footnotetext{
${ }^{39}$ En las Argonáuticas, Apolonio de Rodas recordaba cómo el músico, quien se embarcó con Jasón en la nave Argos, hizo enmudecer el melodioso canto de las sirenas con los sonidos emitidos por su instrumento (ApOlOnio De RodAs, Argonáuticas, Madrid, 2000, IV, vv. 895-920).

${ }^{40}$ P. Ovidio, Metamorfosis, Madrid, 2001, V, v. 555.

${ }^{41}$ F. Buffiere, Les Mythes d'Homère..., p. 385.
} 
estudio, Buffière vincula esta interpretación al platónico Amonio y a Plutarco y apunta que las sirenas no querían acabar con Ulises sino, por el contrario, salvarlo, haciendo que olvidara las cosas mortales y liberara así su alma ${ }^{42}$. Es ésta la razón por la que el prudente Ulises, cuando escuchó el melodioso canto de las sirenas, quiso ir tras ellas. Este héroe griego encarna, según esta interpretación, al sabio que quiere abandonar su cuerpo para ir tras las esferas celestes, tras la armonía eterna; mientras, su tripulación rema sin escuchar nada y preocupada sólo por lo material, siendo la cera que tapona sus oídos un símbolo de lo carnal y lo pasional $^{43}$. Esta consideración de las sirenas como seres benévolos y vinculados a la sabiduría se mantuvo, aunque de manera minoritaria, entre los tratadistas medievales. Ésta fue la interpretación que les dio Guillaume le Clerc de Normandie en el siglo XIII cuando afirmó, como ya señalamos páginas atrás, que las sirenas simbolizaban no sólo la lujuria sino también la gloria $^{44}$.

La conexión que se establece en este emblema entre la sirena e Isócrates partiría por tanto de la vinculación entre ambos y la oratoria $^{45}$. La utilización del ser mitológico sería tan sólo una forma de enfatizar la facilidad de palabra del orador griego. Esta misma interpretación de la sirena es la que realiza el tratadista barroco Andrés Ferrer de Valdecebro en uno de los jeroglíficos que incluye en el libro que dedica a las "Propiedades de el can". Se trata de una breve des-

\footnotetext{
-

${ }^{42}$ F. Buffiere, Les Mythes d'Homère..., p. 478.

${ }^{43}$ F. BUfFIERE, Les Mythes d'Homère..., p. 481. 109.

${ }^{44}$ J. LECLERCQ-MARX, La Sirène dans la pensée..., p.

${ }^{45}$ Cesare Ripa se refiere a Isócrates en su alegoría de la "Poesía", en la que denomina la casa del ateniense como "fragua y asiento de la elocuencia" y afirma que "(d)omus Isocratis quasi ludus quidam atque officina dicendi", o lo que es lo mismo, "La casa de Isócrates fue, por así decir, una especie de escuela y taller del decir" (C. RIPA, Iconología..., II, p. 220).
}

cripción en la que tan sólo dice: “(1)as Syrenas cantando; y esta, Dulce naufragium. Encantan con lo dulce, y sonoro de su voz à los navegantes; ha de suspender el Orador à sus oyentes ${ }^{\prime 46}$.

En este emblema, al igual que en los anteriores analizados, se ofrece una imagen de la sirena muy alejada de la que se podía encontrar en la mayor parte de las representaciones que se realizaron en el Renacimiento y Barroco. La música armoniosa que realiza la sirena en el emblema de Peacham no sólo no es objeto de desconfianza, como se advertía repetidamente desde el poema de Homero, sino que es vinculada a la elocuencia y a la sabiduría y es conectada con uno de los grandes filósofos de la Antigüedad. Tanto en este emblema como en los anteriormente comentados se destacaron unos valores en las sirenas que no pudieron, en ninguno de los casos, competir con la interpretación repetida desde la moral religiosa, la que veía en ellas un símbolo del pecado.

-

46 A. FERRER De VALDECEBro, Gobierno General, Moral, y Politico hallado en las fieras, y animales silvestres, sacado de sus naturales propiedades, y virtudes, con particular tabla para sermones varios de templo, y de santos, Madrid, 1680, p. 332. Frente a esta interpretación se situaría la ofrecida por Luis Alfonso de Carvallo en su Cisne de Apolo. Este autor conectó las sirenas a la figura del mal poeta, a aquél que emplea su talento en torpezas y necedades; como afirma, tanto las sirenas como él “engañan con la dulçura de su canto a los navega[n]tes que fluctuando andan en este mar del mundo, adurmiendo con la vana suavidad de sus vozes, a los que tienen necesidad de quien les despierte en el camino y navegacion de la virtud" (L. A. DE CARVAllo, Cisne de Apolo, Madrid, 1958 (repr. ed. Medina del Campo, 1602), II pp. 223-224). 


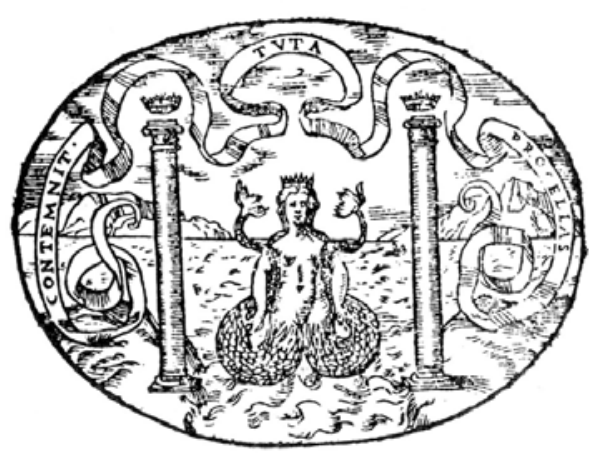

Il Signor Stefano Cslonna valorofo e magnanimo Capitan Gencrale del Duca Cofimo, portando per imprefa la Sirena, antico Cimiero di cafa Colon. $n a, m i$ richiefe alla domeftica (come cornpare clio gliera) ch' io gli vole ßi fare vn motto per appropriarfi per imiprefa la detta Sirena, comune à fua cafa. E cosi conformädomi col fuo generofo penficro, glifecis CONTEMNIT TVTA PROCBLLA9, VO.

bendo dire, ch'egli prezzaua l'aunerfità, con me confidatofi nel valor fucsnel modo, she quella col fuo nuotare fus. pera ogni tempefta.

- Lám. 1. Paolo Giovio. “Contemnit Tuta Procellas". Dialogo dell'Imprese Militari et Amorose (Venecia, 1557). Bibliothèque Nationale (France)

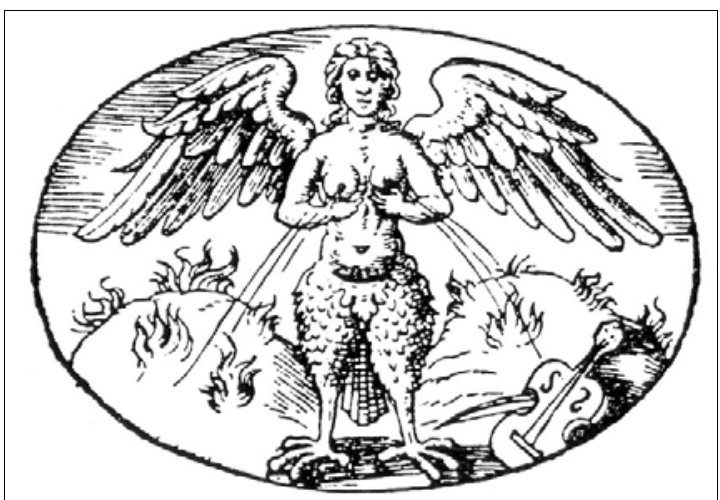

- Lám. 3. Giulio Cesare Capaccio. Trattato dell'Imprese (Nápoles, 1592). Bayerischen Staatsbibliothek-Múnich.

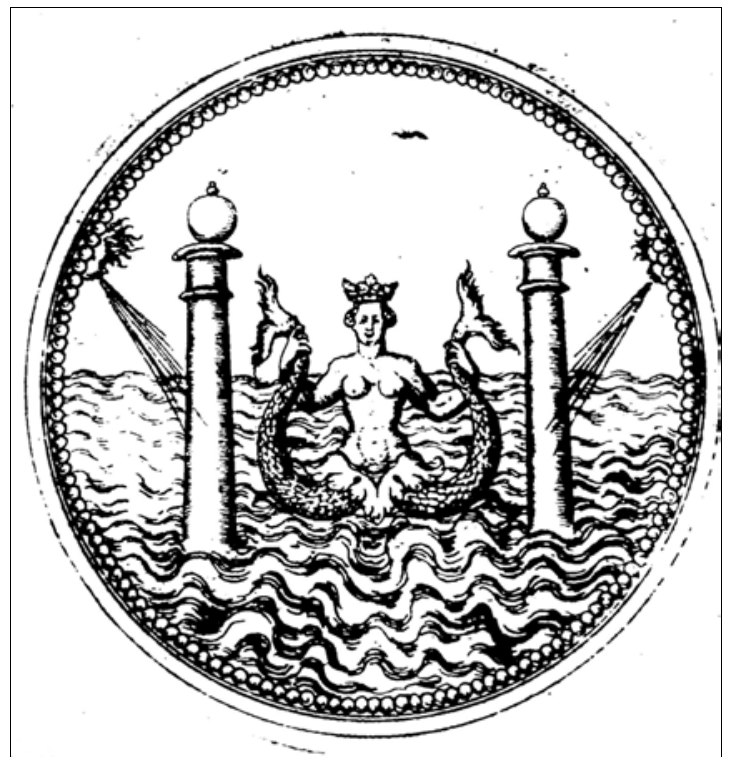

- Lám. 2. Joachim Cameraius. “Contemnit Tuta Procellas". Symbolorum \& Emblematum... (Nuremberg, 1605). Bibliothèque Nationale (France).

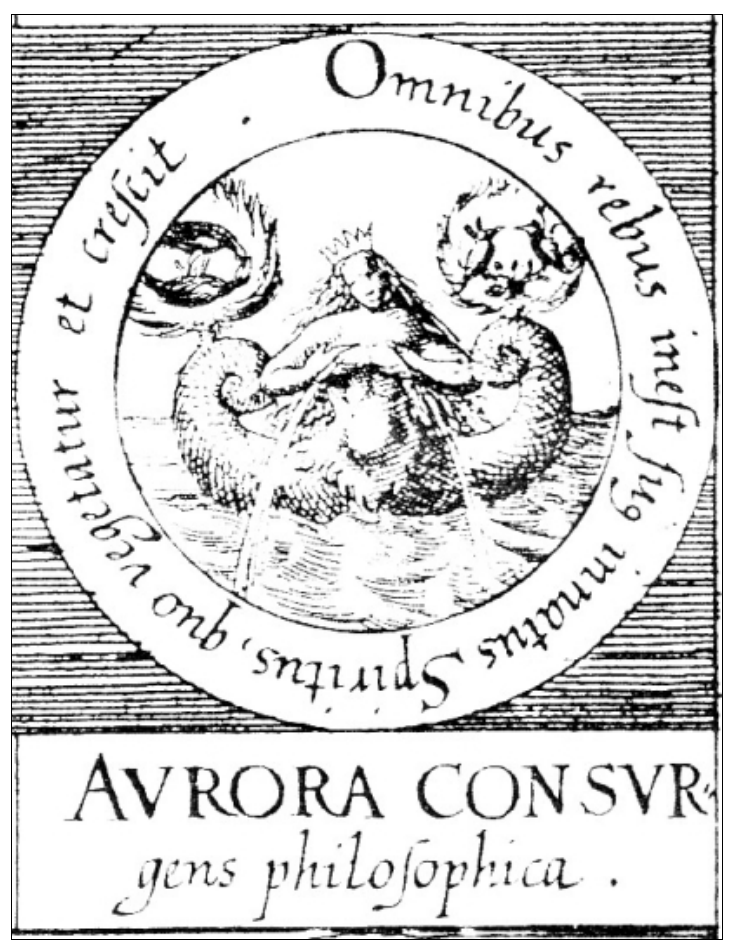

- Lám. 4. Johann Daniel Mylius. “Aurora Consurgens philosophica". Opus medico-chymicum (Frankfurt, 1618). S. SEBASTIÁN, Alquimia y Emblemática. La fuga de Atalanta de Michael Maier, Madrid, 1989. 


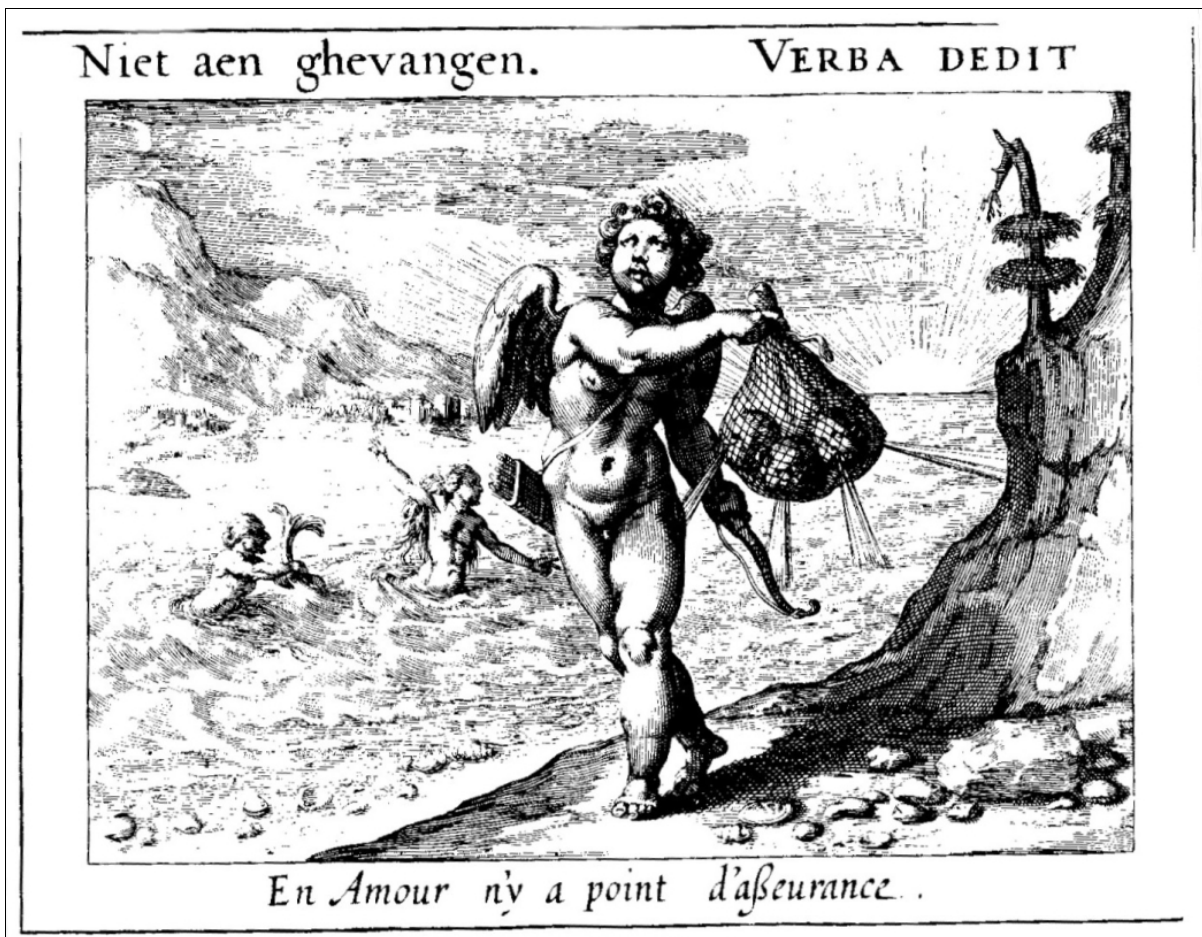

- Lám. 5. Pieter Cornelisz Hooft Emblemata Amatoria, Afbeeldingen van Minne, Emblesmes d'Amour (Ámsterdam, 1611). Leyden University.

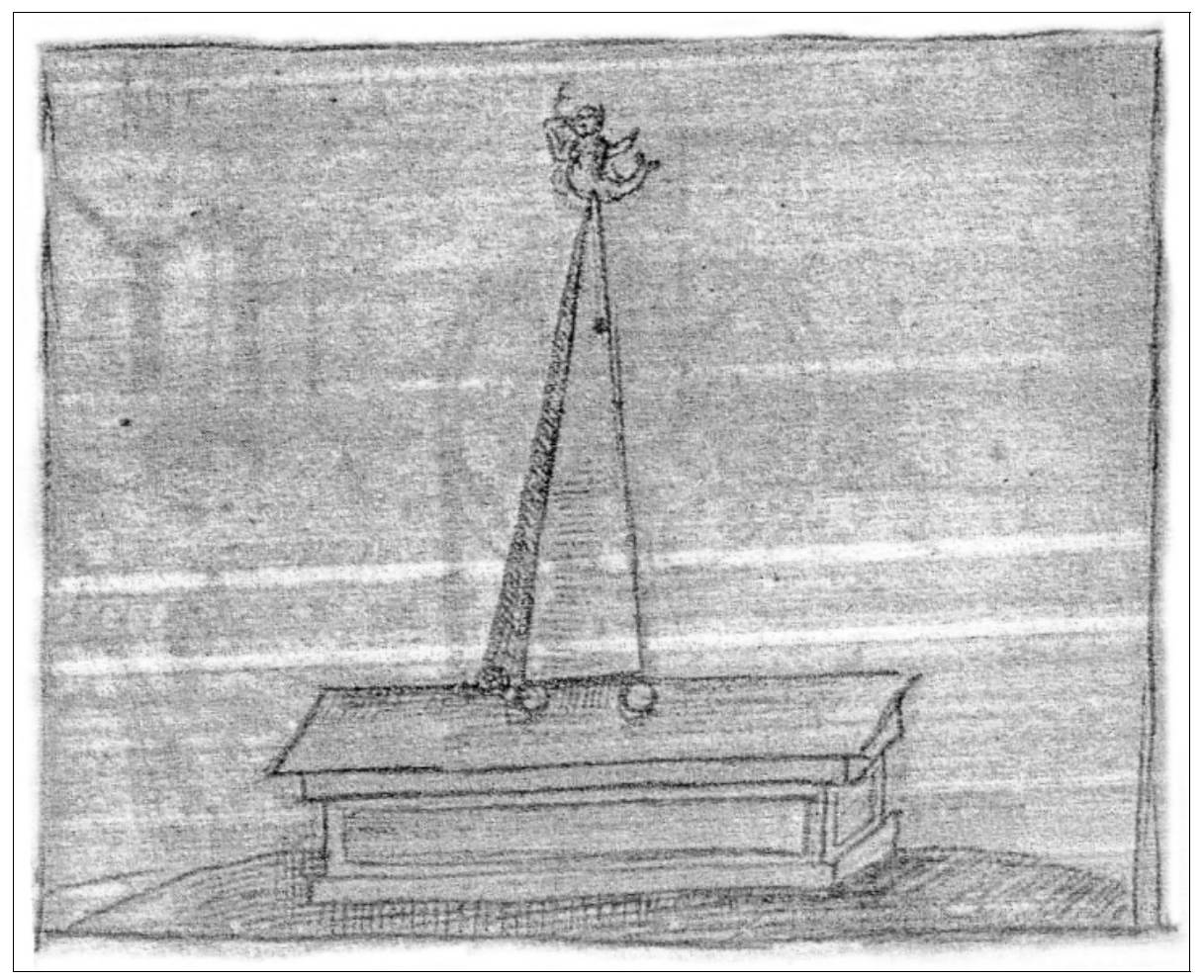

- Lám. 6. Henry Peacham. "Sepulchrum Isocratis". Emblemata varia (ca. 1621). H. PEACHAM, Emblemata Varia (J. Horden, ed.), London, 1976. 